\title{
Identification and characterization of a novel Iraqi isolate of Fusarium pseudograminearum causing crown rot in wheat
}

\author{
M.A. Hameed ${ }^{1,2}$, R.M. Rana $^{3}$ and Z. Ali ${ }^{2,4}$ \\ ${ }^{1}$ Date Palm Research Center, University of Basra, Basra, Iraq \\ ${ }^{2}$ Faculty of Agriculture, Food and Natural Resources, University of Sydney, \\ Sydney, Australia \\ ${ }^{3}$ State Key Lab of Crop Genetics and Germplasm Enhancement, \\ Nanjing Agricultural University, Nanjing, P.R. China \\ ${ }^{4}$ Department of Plant Breeding and Genetics, University of Agriculture, \\ Faisalabad, Pakistan \\ Corresponding author: M.A. Hameed \\ E-mail:malsamir@hotmail.com
}

Genet. Mol. Res. 11 (2): 1341-1348 (2012)

Received May 25, 2011

Accepted November 23, 2011

Published May 15, 2012

DOI http://dx.doi.org/10.4238/2012.May.15.4

ABSTRACT. Crown rot is one of the main important fungal diseases
affecting wheat in many areas of the world, including Australia, USA,
and Iran. Until now, there had been no report of this pathogen in
Iraq. Plants displaying crown rot symptoms were observed in Shaat
Alarab (Basra, Iraq); we investigated the causal agent of the disease.
Samples were surface-sterilized in bleach (1\% available chlorine) and
cultured on quarter-strength potato dextrose agar plates. DNA was
extracted from fungal mycelia, using a modified CTAB protocol. The
ITS/5.8S regions were amplified using primer pair ITS1 and ITS4.
PCR products purified using a gel extraction kit were sequenced. The
sequence that was detected was used to BLAST against NCBI data.
The most similar sequence was the ITS/5.8S rDNA region of Fusarium
pseudograminearum (strain NRRL28062), showing $97.95 \%$ identity.
This species normally causes crown rot, resulting in severe damage 
under dry spring conditions. A pathogenicity test employed to assess the disease-causing ability of the strain showed significant disease symptoms up to $57 \%$ infected spikelets. The results confirmed the presence of $F$. pseudograminearum as a causal agent of wheat crown rot in Iraq. The presence of this pathogen demands further investigations to develop resistant cultivars and/or mechanical control.

Key words: Spring wheat; Sequence; Phylogeny; PCR identification

\section{INTRODUCTION}

Crown rot, caused by Fusarium pseudograminearum, is emerging as an important disease internationally, and has been reported in the Pacific Northwest of the USA (Smiley et al., 2005), South Africa (VanWyk et al., 1987), Italy, Egypt and Syria (Burgess et al., 2001), Turkey (Bentley et al., 2004), West Asia and North Africa (Mitter et al., 2006), and Western Canada (Mishra et al., 2006). Crown rot was first recorded in Australia in 1951, but the cause was unknown (McKnight and Hart, 1966). During the 1960s, the pathogen associated with crown rot was described as Fusarium graminearum Schwabe (McKnight and Hart, 1966; Purss, 1966). Further investigations on isolates of $F$. graminearum Schwabe established two distinct populations (groups) of $F$. graminearum Schwabe (Francis and Burgess, 1977): Group 1 causing crown rot in wheat and Group 2 causing stalk rot of maize and head blight of wheat. Since then, the pathogen associated with crown rot was identified as F. graminearum Group 1 (Fg G1).

The existence of these subspecific groups was further confirmed by using restriction fragment length polymorphism (RFLP) to analyze differences between several Fusarium species (Benyon et al., 1995). Further studies conducted on morphological characters and DNA sequences of Group 1 and Group 2 strains from different geographical regions showed that the Group 1 isolates represent a distinct species called F. pseudograminearum sp nov (Fpg; Aoki and O'Donnell, 1999).

Over the past few years, F. pseudograminearum has emerged as a major causal agent of crown rot disease in cereal crops in various parts of the world, resulting in a reduction of both grain yield and grain quality due to contamination with mycotoxins (reviewed by Mishra et al., 2006). To our knowledge, there is no report about this pathogen causing wheat crown rot in Iraq. The present study was planned to investigate the causal agent for the crown rot observed at Shaat Alarab (Basra, Iraq). We used PCR amplification of internal transcribed spacer (ITS) regions 1 and 4, and sequencing of the PCR product to identify the species. Diseasecausing ability of the isolated strain was confirmed by a pathogenicity test.

\section{MATERIAL AND METHODS}

\section{Isolate collection and culture}

Ten samples were collected from wheat plants at maturity displaying crown rot symptoms from Shatt Al-Arab near Basra (latitude: $30^{\circ} 28^{\prime} 20 \mathrm{~N}$, longitude: $47^{\circ} 58^{\prime} 55 \mathrm{E}$ and $4 \mathrm{~m}$ asl), Iraq. Sections of $2 \mathrm{~mm}$ in diameter were removed from infected crown tissues to be used for fungal isolations. The tissues were surface-sterilized in bleach (1\% available chlorine) 
for $5 \mathrm{~min}$, rinsed twice in sterile water for $5 \mathrm{~min}$ and blot dried on sterile filter paper. Crowninfected sections were then cultured onto quarter-strength potato dextrose agar (PDA) plates containing $100 \mu \mathrm{g} / \mathrm{mL}$ streptomycin sulfate and $10 \mu \mathrm{g} / \mathrm{mL}$ tetracycline hydrochloride. Cultures were incubated at ambient light and temperature for 7-10 days. Plates were then flooded with sterile distilled water and the resultant spore suspension streaked onto water agar plates using a flame-sterilized metal loop. Water-agar cultures were maintained under ambient conditions for 12-24 h. A single germinating macroconidium was transferred to a fresh quarter-strength PDA plate for each isolate. Monoconidial cultures were maintained at $25^{\circ} \mathrm{C}$ under ambient light for 14 days and stored as $1-\mathrm{cm}^{2}$ agar plugs using $15 \%$ glycerol at $-80^{\circ} \mathrm{C}$ until further use. To obtain large quantities of mycelia for DNA isolation, $600-\mathrm{mL}$ Roux culture flasks containing $25 \mathrm{~mL}$ clarified liquid $\mathrm{V} 8$ media $\left(10 \% \mathrm{~V} 8\right.$ juice and $\mathrm{CaCO}_{3}$ at $\left.1 \mathrm{~g} / \mathrm{L}\right)$ were inoculated with four $1-\mathrm{cm}^{2}$ agar plugs from actively growing fungal cultures and grown for 7 days at $22^{\circ} \mathrm{C}$. Mycelium was collected and washed with sterile distilled water (SDW) three times and then freeze-dried until further use.

\section{DNA extraction}

DNA was extracted using a modified CTAB protocol (Moller et al., 1992). The prepared fungal mycelium $(50 \mathrm{mg}$ ) was recovered from the freezer and homogenized using a TissueLyser II (QIAGEN) in 2-mL microcentrifuge tubes at a speed of $28 \mathrm{~Hz}$. A volume of $500 \mu \mathrm{L}$ pre-heated $\left(65^{\circ} \mathrm{C}\right)$ TES lysis buffer $[100 \mathrm{mM}$ Tris, $\mathrm{pH} 8.0 ; 10 \mathrm{mM}$ ethylenediaminetetraacetate (EDTA), $\mathrm{pH} 8.0 ; 2 \%$ (w/v) sodium dodecyl sulfate (SDS)] was added to the homogenized material, and after mixing by inversion, $50 \mu \mathrm{g}$ proteinase $\mathrm{K}$ was added. The suspension was then incubated at $65^{\circ} \mathrm{C}$ for $30 \mathrm{~min}$. Next, $140 \mu \mathrm{L} 5 \mathrm{M} \mathrm{NaCl}$ and $64 \mu \mathrm{L} 10 \%$ (w/v) cetyltrimethylammonium bromide (CTAB) were added and the tubes incubated at $65^{\circ} \mathrm{C}$ for $10 \mathrm{~min}$. An equal volume of chloroform:isoamyl alcohol (24:1) was added to the mixture and the tubes centrifuged at 13,000 $\mathrm{g}$ for $10 \mathrm{~min}$. The upper aqueous phase was transferred to a fresh tube. Chilled isopropanol (equal volume) and 0.1 volume $3 \mathrm{M}$ sodium acetate, $\mathrm{pH} 5.2$, were added to the supernatant and the mixture incubated at $-20^{\circ} \mathrm{C}$ for at least $30 \mathrm{~min}$. The DNA pellet was obtained by centrifugation at $14,000 \mathrm{~g}$ for $15 \mathrm{~min}$. The DNA pellet was washed twice with cold $70 \%$ ethanol, air dried and suspended in $100 \mu \mathrm{L}$ TE $(10 \mathrm{mM}$ Tris, $\mathrm{pH} 8.0 ; 1 \mathrm{mM}$ EDTA, $\mathrm{pH}$ 8.0). RNA was digested by adding $10 \mathrm{mg} / \mathrm{mL}$ RNase $A$ and the mixture incubated at $37^{\circ} \mathrm{C}$ for 45 min. Extracted DNA was stored at $-20^{\circ} \mathrm{C}$ until further use.

\section{PCR amplification of ITS/5.8S regions}

The ITS/5.8S regions were amplified using the primer pair ITS1 (5'-TCCGTAGGT GAACCTGCGG-3'), which hybridizes to the end of 18S rDNA, and ITS4 (5'-TCCTCCGCT TATTGATATGC-3'), which hybridizes to the beginning of 28S rDNA (Ferrer et al., 2001). Amplification was carried out in a $25-\mu \mathrm{L}$ reaction mixture containing $1 \mathrm{X}$ PCR buffer, $2.5 \mathrm{mM}$ $\mathrm{MgCl}_{2}, 0.6 \mathrm{mM}$ of each dNTP, $0.25 \mu \mathrm{M}$ of each primer, $1.25 \mathrm{U}$ Taq polymerase (Promega) and $4 \mathrm{ng}$ genomic DNA. PCR was performed in a thermal cycler (MJ research, PTC-100). PCR cycling profile was as follows: hot start at $95^{\circ} \mathrm{C}$ for $5 \mathrm{~min}, 35$ cycles of $95^{\circ} \mathrm{C}$ for $1 \mathrm{~min}, 55^{\circ} \mathrm{C}$ for 1 min and $72^{\circ} \mathrm{C}$ for $2 \mathrm{~min}$, and a final extension at $72^{\circ} \mathrm{C}$ for $10 \mathrm{~min}$. PCR products were resolved on a $1 \%(\mathrm{w} / \mathrm{v})$ agarose gel (with ethidium bromide, $10 \mathrm{ng} / 100 \mathrm{~mL}$ ). The fingerprints were ex- 
amined under an ultraviolet transilluminator (SynGen, Synoptics Ltd., UK) at $300 \mathrm{~nm}$. The approximate size of the amplified product was estimated using a 100-bp marker (MBI Fermentas).

\section{DNA sequencing of PCR products}

Amplified DNA from PCR was purified using the QIAquick Gel Extraction kit (QIAGEN) as specified by the manufacturer and directly cycle sequenced in both directions using the BigDye terminators Ready Reaction kit (PE Applied Biosystems, Foster City, CA, USA) on an ABI Prism automated DNA sequencer (model 377, version 2.1.1; Applied Biosystems, Warrington, UK) using ITS1 and ITS4 primers.

\section{Negative control}

Two negative controls were included in the amplification: a reagent control (sterile water) and a sample extraction control. The sample extraction control consisted of sterile water subjected to the same extraction procedures as the specimens.

\section{Disease assessment}

Wheat plants were inoculated at seven days post-anthesis (DPA) using a conidial suspension of $1 \mathrm{~L} / 100 \mathrm{ft}^{2}$ at 50,000 spores/mL (Chappell et al., 1999). After inoculation, overhead mist irrigation was applied to maintain epidemic conditions. Percentage of infected spikelets was recorded at 14 days after inoculation (DAI) derived from the number of spikelets infected and the total number of spikelets.

\section{Data analysis}

F. pseudograminearum fungi, for which the rDNA sequence is available in GenBank, were assayed for selected primer hybridization using the PCGENE program that facilitates the positive or negative in silico binding of primers to the sequence target. After Clustal alignment of the selected sequences, fragment sizes were manually calculated. ITS2/5.8S rDNA sequences were analyzed by using the BLAST program of the GenBank database, National Institutes of Health. The alignment provides a list of matching organisms, ranked in order of similarity between the unknown sequence and the sequence of the corresponding organism from the database.

\section{RESULTS}

\section{PCR specificity}

The primers used in this study (ITS1 and ITS4) successfully amplified DNA from fungal isolates, and the fragment obtained was about $280 \mathrm{bp}$ (Figure 1). No amplification products were detected by using the ITS1-ITS4 primer pairs with genomic DNA isolated from wheat or from Escherichia coli. Fungi were tested with the PCGENE program to ascertain the specificity of this method. The sizes of the fragments obtained were in agreement with those obtained by PCR. 


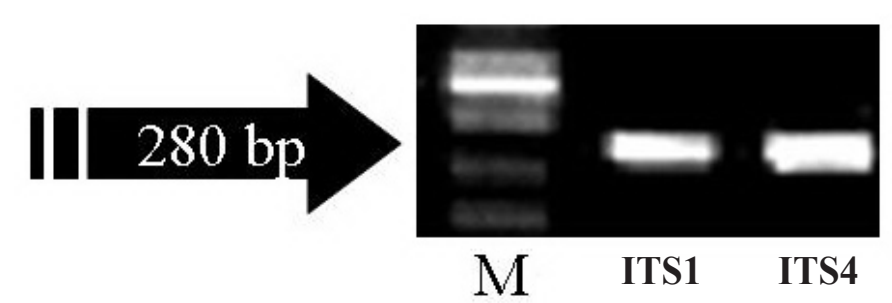

Figure 1. Electrophoresis pattern of ITS/5.8S regions amplified using primer pairs ITS1 and ITS4. Lane $M=$ molecular marker

\section{DNA sequencing and phylogenetic analysis}

The DNA fragment obtained representing full-sequence ITS/5.8S rDNA was purified by gel extraction method and sequenced. The sequence results from all 10 crown rot samples when compared to DNA database demonstrated that they were derived from the fungal ITS regions. All the sequenced samples were alike in their sequence. To identify the species, a sequence similarity search was performed using BLAST (Basic Local Alignment Search Tool) at the NCBI website (http://blast.ncbi.nlm.nih.gov/Blast.cgi). BLAST search was performed against the fungal genome and maximum number results were limited up to the 50 most relevant sequences. Results revealed that the most identical sequence was ITS/5.8S rDNA region of F. pseudograminearum (strain NRRL28062; sequence ID DQ459871) showing 97.95\% identity (Figure 2), while the other sequences showed low similarity.

\section{A}

\section{B}
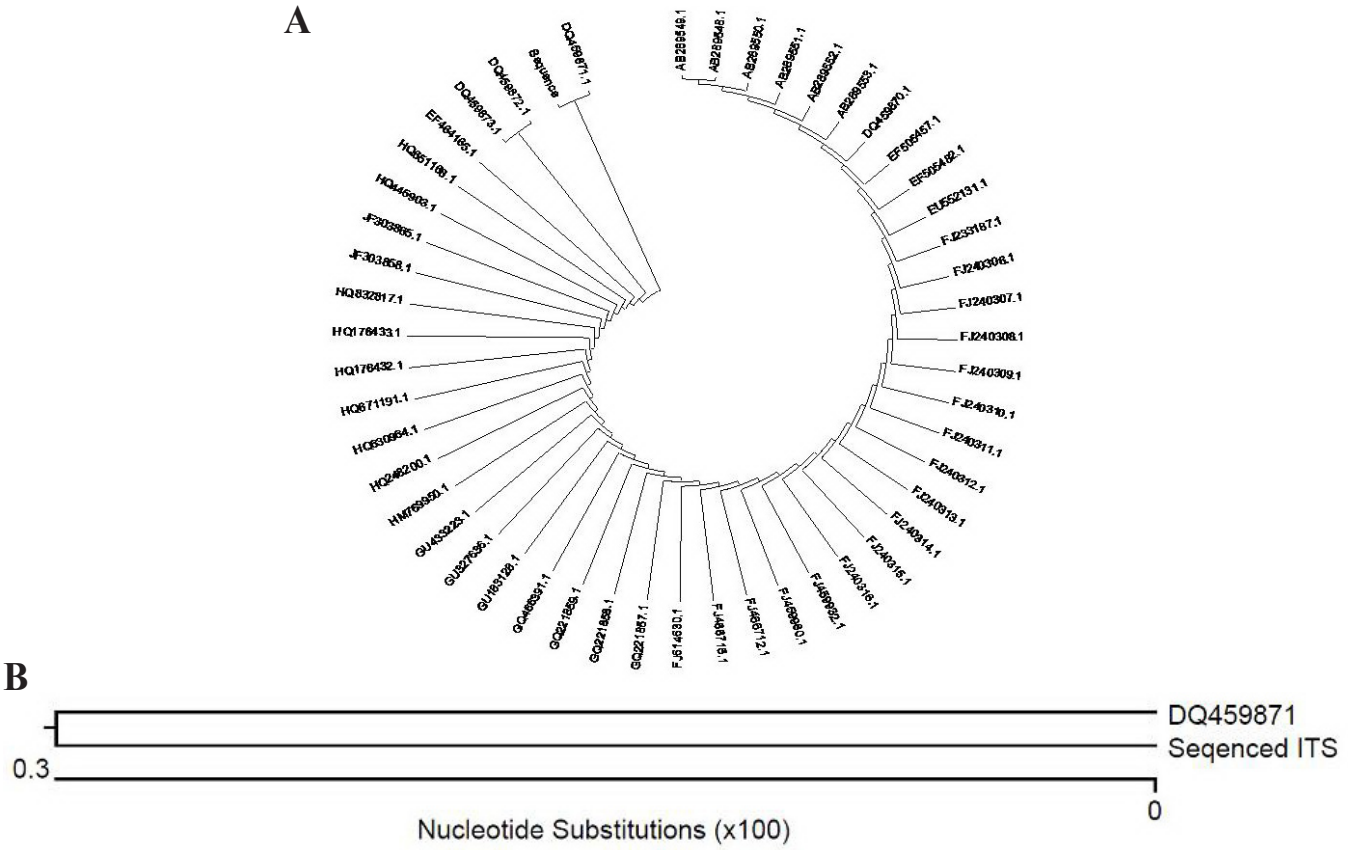

Figure 2. Evolutionary relationships of Fusarium pseudograminearum. A. Most identical sequence. B. Fifty most related sequences. 


\section{Disease assessment}

To further confirm the pathogenicity of the isolated/identified isolate, a pathogenicity test was applied. The fungal isolate used to inoculate 7 DPA wheat spikelets was observed for disease-causing ability of the isolate. The wheat spikelets observed 14 DAI showed significant disease symptoms for crown rot and 57\% infected spikelets were observed.

\section{DISCUSSION}

The PCR-based method, quicker and more sensitive than whole seed agar plating, can distinguish between morphologically similar species such as $F$. graminearum and $F$. pseudograminearum and $F$. acuminatum ssp acuminatum and $F$. avenaceum ssp avenaceum (Demeke et al., 2005). Among other regions used for phylogenetic classification of fungi, ITS regions are typically variable and quite informative (Diaz and Fell, 2004). The ability of the ITS region to differentiate within Fusarium species has been reported as a reliable and faster way to discriminate the isolates at both the genus and species level (Oechsler et al., 2009).

In this study, we isolated and identified the causative agent of wheat crown from the wheat plants displaying crown rot symptoms at Shaat Alarab (Basra, Iraq), using ITS region amplification and sequencing followed by a pathogenicity test.

The primers used in this study (ITS1 and ITS4) successfully amplified DNA from fungal isolates, and the fragments obtained were purified and sequenced. The sequence results when compared to the database demonstrated that they were derived from the fungal ITS regions. BLAST results showed that the most identical sequence was ITS/5.8S rDNA region of F. pseudograminearum (strain NRRL28062), with $97.95 \%$ identity. This result from sequence similarity established that the isolated strain belonged to the species F. pseudograminearum. To further confirm the disease-causing ability of the isolate, we conducted a pathogenicity test. The fungal isolate was used to inoculate wheat spikelets and observed for disease causingability of the isolate. The wheat spikelets showed significant disease symptoms for crown rot and $57 \%$ infected spikelets were observed (data not shown). Based on the above results, it was established that the causal agent of the wheat crown rot was F. pseudograminearum, and to our knowledge this is the first report about this species in Iraq. The ITS region sequence of the isolate has been submitted to the NCBI database and assigned GenBank accession No. JN007071.

Over the past few years, F. pseudograminearum has emerged as a major causal agent of crown rot disease. The pathogen has been reported to be prevalent in drought where soil moisture has been low as reported during the last 12 years in Southern Australia (Luck et al., 2011). Interaction of crown rot with soil moisture has been extensively studied in Australia (Wildermuth et al., 1997) and the United States (Smiley et al., 2005). Crown rot severity increases with moisture stress and post-anthesis moisture stress results in the expression of 'whiteheads' (Burgess et al., 2001). In past few years, drought has been observed in several Asian countries, including Iraq, Jordan, Syria, and Iran (reviewed by Trigo et al., 2010). In Iran, F. pseudograminearum has been reported as a major causal agent of crown rot and showed privilege to drought conditions (Saremi et al., 2007).

As F. pseudograminearum is a soil-borne fungus the incidence of crown rot disease is mostly correlated with stubble management as the fungus survives in infected residues 
(Wearing and Burgess, 1977). Saremi et al. (2007) showed that development of crown rot disease was more severe in poor soils than in soils rich in organic matter. Crop rotation and stubble burning can help to minimize the incidence of disease. The solarization method can be effectively used to control F. pseudograminearum as already used for controlling different soil-borne plant pathogens in several countries, including Iraq, Greece, Italy, and others (Al-Ahmad, 1993; Hall, 1996), since high temperatures generated in soil can kill pathogens. Solarization coupled with deep plowing can further reduce the survival chances of soil-borne pathogens.

\section{CONCLUSION}

In conclusion, the results established the presence of $F$. pseudograminearum, an Iraqi isolate, causing crown rot in wheat in Iraq. This is the first report about the presence of this species in Iraq. The PCR/sequencing method successfully detected the fungal pathogen by amplification, sequencing and comparing sequence similarity of ITS region, which was likewise confirmed through the disease-causing ability of the isolate. Detection of this new causal agent of wheat crown rot in Iraq should prompt plant pathologists to further investigate this fungus and develop preventive measures including the development of resistant cultivars.

\section{REFERENCES}

Al-Ahmad MA (1993). The solar chamber: an innovative technique for controlling verticillium wilt of olive. EPPO Bull. 23: 531-535.

Aoki T and O'Donnell K (1999). Morphological characterization of Gibberella coronicola sp. nov., obtained through mating experiments of Fusarium pseudograminearum. Mycoscience 40: 443-453.

Bentley AR, Griffiths SP, Burgess LW and Summerell BA (2004). Austrostipa aristiglumis (Plains grass) as an Intermediate Host of Fusarium pseudograminearum and other Fusarium species. Proceedings of the 3rd Australasian Soilborne Diseases Symposium (KMOH Keller BH, ed.). South Australian Research and Development Institute, Adelaide.

Benyon F, Burgess L and Sharp P (1995). Molecular Variation Amongst Fusarium species Responsible for Crown Rots of Winter Cereals in Relation to their Pathogenicity and Morphological Characteristics. In: International Seminar on Fusarium: Mycotoxins, Taxonomy and Pathogenicity, Martina Franca.

Burgess LW, Backhouse D, Summerell BA and Swan LJ (2001). Crown Rot of Wheat. In: Fusarium: Paul E. Nelson Memorial Symposium (Summerell BA, Leslie JF, Backhouse D, Bryden WL, et al., eds.). American Phytopathological Society Press, Saint Paul, 271-294.

Chappell M, Griffey C, Pridgen T, Chen J, et al. (1999). Assessment and Reaction of Soft Red Winter Wheat Genotypes to Fusarium graminearum and Effects on Traits Related to Yield and Seed Quality. Proceedings of the National Fusarium Head Blight Forum, Sioux Falls, 143-145.

Demeke T, Clear RM, Patrick SK and Gaba D (2005). Species-specific PCR-based assays for the detection of Fusarium species and a comparison with the whole seed agar plate method and trichothecene analysis. Int. J. Food Microbiol. 103: 271-284.

Diaz MR and Fell JW (2004). High-throughput detection of pathogenic yeasts of the genus Trichosporon. J. Clin. Microbiol. 42: 3696-3706.

Ferrer C, Colom F, Frases S, Mulet E, et al. (2001). Detection and identification of fungal pathogens by PCR and by ITS2 and 5.8S ribosomal DNA typing in ocular infections. J. Clin. Microbiol. 39: 2873-2879.

Francis RG and Burgess L (1977). Characteristics of two populations of Fusarium roseum 'Graminearum' in Eastern Australia. Trans. Br. Mycol. Soc. 68: 421-427.

Hall R (1996). Principles and Practice of Managing Soilborne Plant Pathogens American Phytopathological Society. APS Press, Saint Paul.

Luck J, Spackman M, Freeman A, Trebicki P, et al. (2011). Climate change and diseases of food crops. Plant Pathol. 60: 113-121.

McKnight T and Hart J (1966). Some field observations on crown rot disease of wheat caused by Fusarium graminearum. Queensl. J. Agr. Anim. Sci. 23: 373-378. 
Mishra PK, Tewari JP, Clear RM and Turkington TK (2006). Genetic diversity and recombination within populations of Fusarium pseudograminearum from western Canada. Int. Microbiol. 9: 65-68.

Mitter V, Zhang M, Liu C, Ghosh R, et al. (2006). A high throughput glasshouse bioassay to detect crown rot resistance in wheat germplasm. Plant Pathol. 55: 433-441.

Moller EM, Bahnweg G, Sandermann H and Geiger HH (1992). A simple and efficient protocol for isolation of high molecular weight DNA from filamentous fungi, fruit bodies, and infected plant tissues. Nucleic Acids Res. 20: 61156116.

Oechsler RA, Feilmeier MR, Ledee DR, Miller D, et al. (2009). Utility of molecular sequence analysis of the ITS rRNA region for identification of Fusarium spp. from ocular sources. Invest. Ophthalmol. Vis. Sci. 50: 2230-2236.

Purss G (1966). Studies of varietal resistance to crown rot of wheat caused by Fusarium graminearum Schw. Queensl. J. Agr. Anim. Sci. 23: 475-598.

Saremi H, Ammarellou A and Jafary H (2007). Incidence of crown rot disease of wheat caused by Fusarium pseudograminearum as a new soil born fungal species in north west Iran. Pak. J. Biol. Sci. 10: 3606-3612.

Smiley RW, Gourlie JA, Easley SA and Patterson LM (2005). Crop damage estimates for crown rot of wheat and barley in the Pacific Northwest. Plant Dis. 89: 595-604.

Trigo RM, Gouveia CM and Barriopedro D (2010). The intense 2007-2009 drought in the Fertile Crescent: Impacts and associated atmospheric circulation. Agr. Forest Meteorol. 150: 1245-1257.

VanWyk PS, Los O, Pauer GDC and Marasas WFO (1987). Geographic distribution and pathogenicity of Fusarium species associated with crown rot of wheat in the Orange Free State, South Africa. Phytophylactica 19: 271-274.

Wearing A and Burgess L (1977). Distribution of Fusarium roseum 'Graminearum' Group 1 and its mode of survival in eastern Australian wheat belt soils. Trans. Br. Mycol. Soc. 69: 429-442.

Wildermuth GB, Thomas GA, Radford BJ, McNamara RB, et al. (1997). Crown rot and common root rot in wheat grown under different tillage and stubble treatments in southern Queensland, Australia. Soil Till. Res. 44: 211-224. 